\title{
The Climate Change Impact on Russia's Wind Energy Resource: Current Areas of Research
}

\author{
Sergei Soldatenko1, Lev Karlin² \\ ${ }^{1}$ A.M. Obukhov Institute of the Atmospheric Physics of the Russian Academy of Sciences, Moscow, Russia \\ ${ }^{2}$ Russian State Hydrometeorological University, St. Petersburg, Russia \\ Email: soldatenko@ifaran.ru
}

Received 26 July 2014; revised 20 August 2014; accepted 6 September 2014

Copyright (C) 2014 by authors and Scientific Research Publishing Inc.

This work is licensed under the Creative Commons Attribution International License (CC BY). http://creativecommons.org/licenses/by/4.0/

(c) $\underset{\mathrm{EY}}{\mathrm{B}}$ Open Access

\begin{abstract}
Exploration of the climate change impact on wind energy is a focus of scientific analysis and research in many countries around the world. Previous studies have demonstrated that over the last three decades measured wind in the boundary and surface layer of the atmosphere has changed all over the globe. However, effects of climate change on the wind energy sector of Russia are not well explored. Therefore, the Russian climate change research needs to focus on improving the analysis and prediction of wind characteristics that are most relevant to Russia's wind energy development. This paper analyzes the effects of global climate change on the patterns of the general circulation of the atmosphere, large-scale atmospheric temperature field and dynamics, as well as wind speed in the planetary boundary layer and, in particular, in the atmospheric surface layer, with regards to Russia's geographical location and its climatic characteristics. This paper also explores and discusses current areas of climate change research relevant for estimating the wind energy potential in Russia. Two areas of research are emphasized: study of the impact of global warming on poleward shifts of the large-scale synoptic eddies which strongly affect the weather patterns and wind field over large territories; and the study of the effects of ice melting in Arctic seas which significantly alter the properties of the underlying surface and, thus, speed and direction of wind in the surface layer.
\end{abstract}

\section{Keywords}

Climate Change, Wind Resources, Baroclinic Instability, Synoptic-Scale Eddies, Surface Layer

\section{Introduction}

Wind energy is one of the well-established sources of renewable energy that is currently used in 103 countries 
around the world. According to the key statistics provided by the World Wind Energy Association (WWEA), the world wind energy capacity by the end of 2013 reached 318,529 MW, after 282,275 MW in 2012 [1]. The world total installed wind energy capacity since 1997 is shown in Figure 1 [1]. In 2013 only 35,550 MW of new wind power capacity was added, compared to 44,609 MW added in 2012. Figure 2 illustrates newly installed wind energy capacity from the beginning of 1998 [1]. In 2013 the growth rate of wind power installations has been only $12.8 \%$, the smallest since 1998 . To date, wind power contributes about $4 \%$ to the global electricity demand. WWEA projects that the wind power capacity in 2020 could realistically reach more than 700,000 MW. Further growth of the wind energy has potential to significantly reduce the short-term (2020) and long-term (2050) emissions of greenhouse gases (GHGs) thereby mitigating the climate change and its negative consequences on nature and human society.

For the last few years, the wind energy markets in South America and Eastern Europe have been the most dynamic and experienced the highest growth rates. Russian Federation (RF), being one of the largest by landmass countries in the world, has very high wind energy potential. However, the wind energy development is inhibited by the vast reserves of conventional energy resources and lack of strong political interests and legislative framework to promote renewable energy development. As a result, in 2013 Russia's total installed wind capacity was only 16.8 MW, putting it in 69-th place among all countries. By contrast, in 2013 the installed capacities in China, the USA and Germany, who are the leaders in the development of wind energy, were 91,324, 75,324 and 34,669 MW respectively. Nevertheless, in 2013 the Russian government approved new measures to support renewable energy. In particular, up to 16 new wind farms are to be built across regions of the country. Among these are four wind farms in the Northwestern Federal District: the 300 MW wind farm in the St. Petersburg re-

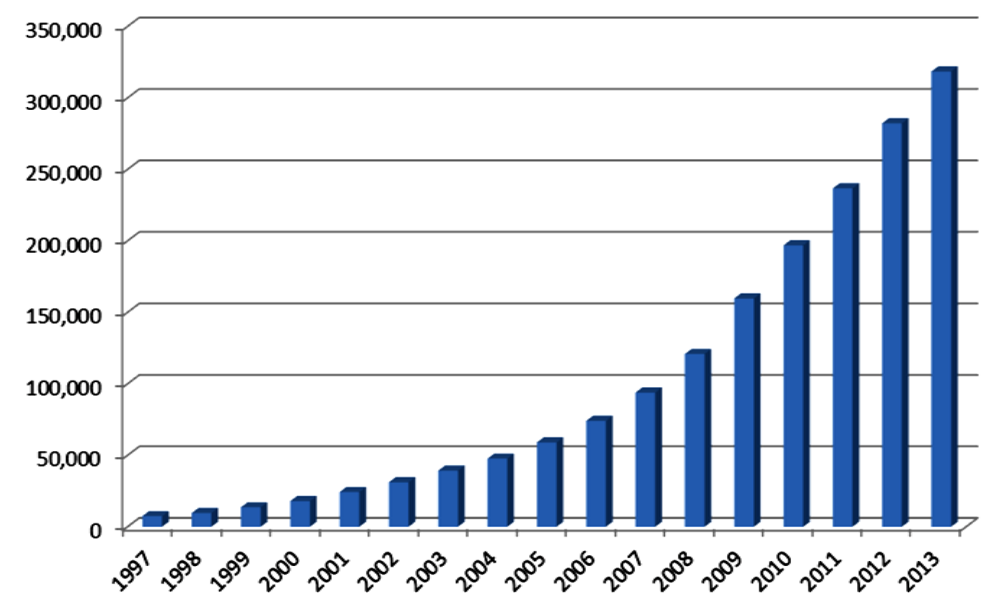

Figure 1. Total installed wind capacity in the world (MW) [1].

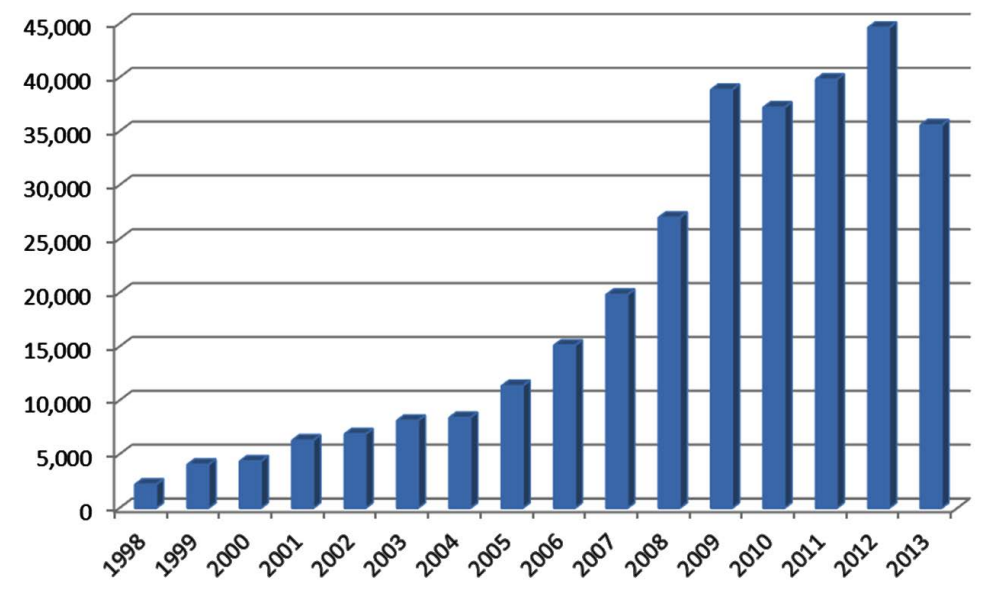

Figure 2. Newly installed capacity (MW) [1]. 
gion, the 200 MW project in the Kaliningrad region, as well as 300 MW and 500 MW projects in the Murmansk region.

A number of previous studies have estimated the global wind power resource. The theoretical wind potential in terms of the global annual flux has been estimated at 6000 EJ/year [2], but the global technical potential for wind energy strongly depends on the technology and assumptions made with respect to various constraints for development of wind farms. Unfortunately, no standardized and approved method has been proposed to estimate the global technical potential of wind energy. In addition, different studies used different meteorological and technical data, approaches and assumptions. Consequently, the obtained estimates differ significantly from one another [3]-[8] and range from $70 \mathrm{EJ} /$ year (19,400 TWh/year) to $3050 \mathrm{EJ} /$ year (840,000 TWh/year) [9].

Two approaches can be used to estimate wind power resources. The first method is based on available climatic wind data. In this approach, average historical wind speed measurements are interpolated on a high-resolution grid to obtain a surface wind distribution. The second approach involves the use of models of the general circulation of the atmosphere, with subsequent applications of high-resolution numerical weather forecasting models and/or downscaling technique. Combinations of these two methods can also be used to estimate the global, regional and local wind energy potential. It is very important, that the estimates of the technical potential for wind energy take into account not only the wind energy technologies but also the state and variability of the Earth's climate system because the driving force of wind energy, the wind speed, is determined by the wide-range spectrum of atmospheric motions, which, in turn, are impacted by many factors such as external radiative forcing.

Detailed analysis of wind energy resource in Russia is presented in [10]. An estimate of the technical wind potential in Russia is more than 50 EJ/year (14,000 TWh/year). The most suitable regions for wind energy development within Russia, as shown in Figure 3 [11], are situated in the western part of the country, western Siberia, the South Ural area, and on the seacoasts of the Arctic and Pacific Oceans. However, in many of these areas population density is less than one person per square kilometer and the existing electricity infrastructure is not sufficiently developed. Opportunities for wind energy development for both small facilities and large wind farms in different parts of Russia were discussed in [12].

Russia's territory covers different climate zones. The global climate change, which is currently observed on our planet, affects different geographical regions differently. Although climate change represents a global phenomenon, its effects are heterogeneous across geographical regions of the world and, in particular, across Russia's territory. The Earth's climate system (ECS) is a complex, interactive, nonlinear dynamical system consisting of the atmosphere, hydrosphere, cryosphere, lithosphere and biosphere. The state of the ECS at a given time and place with respect to variables such as temperature, barometric pressure, wind velocity, moisture, precipitations is known as the weather. Climate is usually defined as "average weather" or, in other words, as an ensemble of states traversed by the climate system over a sufficiently long period of time. Commonly, this period corresponds to $\sim 30$ years, as defined by the World Meteorological Organization. The evolution of the ECS in time is due to both its own internal oscillating processes, such as El Niño-Southern Oscillation (ENSO), and changes in external factors that influence climate system. However, the solar radiation is the fundamental energy source that drives the whole ECS [13]. Thus, the thermal structure of the climate system, its dynamics, as well as tem-

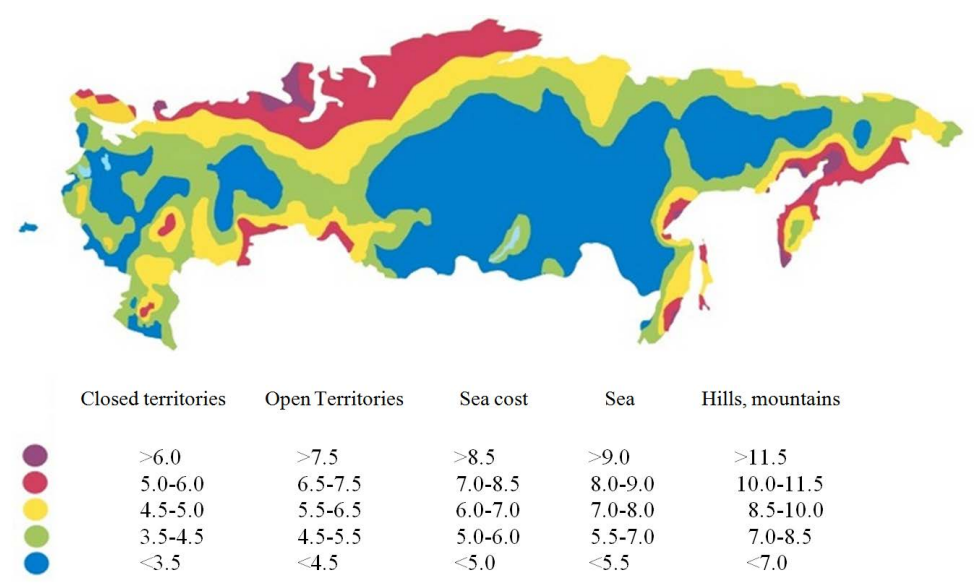

Figure 3. Wind speed at the height of $50 \mathrm{~m}$ above the surface [11]. 
poral and special behavior are significantly influenced by natural and anthropogenic factors that affect the radiation energy balance (energy budget) of the ECS. The Earth's radiation balance represents the accounting of the balance between incoming shortwave radiation, which is almost entirely solar radiation, and outgoing longwave radiation, which is partly reflected solar radiation and partly radiation emitted from the Earth system, including the atmosphere. Changes in the radiation balance of the ECS are governed by:

- variations in the incoming short-wave solar radiation, caused, for instance, by changes in the Earth's orbit;

- fluctuation of the Earth's albedo (reflectivity) due to variations in cloud cover, atmospheric aerosol composition, vegetation, etc.; and

- alteration of the long-wave radiation emitted by the Earth back into the space, caused, for example, by changing greenhouse gas (GHG) concentrations.

Climate reacts directly to such perturbations and also indirectly through positive and negative feedback mechanisms that exist in ECS. According to climate theory, observational data and research findings, the global warming is a man-made phenomenon caused by the increase of concentrations of GHGs such as carbon dioxide $\left(\mathrm{CO}_{2}\right)$ and methane $\left(\mathrm{CH}_{4}\right)$. Observations show that since the beginning of the 20-th century, the Earth's global average surface temperature has increased by almost $0.8^{\circ} \mathrm{C}$, with about two-thirds of the increase occurring since 1980. Presently, global warming is acknowledged by both the scientific community and majority of policymakers. The IPCC Fifth Assessment Report (AR5) provides a distinct view of the up-to-date state of scientific knowledge regarding climate change. It is recognized, that mankind is causing global warming by anthropogenic $\mathrm{CO}_{2}$ emissions generated by human activities through combustion of fossil fuel, mainly coal, oil, natural gas and wood. Due to the burning of fossil fuels and destruction of native forests, the concentration of carbon dioxide is increased from 280 to more than 390 parts per million (ppm) since the beginning of the so-called Industrial Revolution ( 1750).

Generally speaking, Earth's atmosphere is currently overburdened with carbon dioxide, which significantly affects the Earth climate with potentially disastrous consequences. Therefore, the humanity must act now to prevent further increases in the concentration of GHGs and therefore global warming by adopting clean and renewable energy resources such as wind energy, solar energy and bioenergy.

As mentioned above, renewable energy sources depend on the state and variability of the Earth's climate. Thus, the wind energy production is really a function of the ECS' state since surface wind speed is one of the state variables of the ECS. Therefore, if the future behavior of the ECS will be different from how the ECS has evolved in the past, the estimates of renewable energy resources must be periodically updated. Changes in measured surface wind speeds over the last three decades have been discussed in [14] [15]. Since the climate is not stationary, the assessment of resources of renewable energy, including wind energy, based on historical climate data is no longer valid. It is expected that GHG concentrations in the atmosphere will continue to grow. Climate models predict that, depending on the amount of GHG emitted into the atmosphere by human activities, global temperature could further rise by $1^{\circ} \mathrm{C}-5^{\circ} \mathrm{C}$ over the next several decades. Increase GHG concentrations are also expected to reduce ice cover, snow cover and permafrost, raise sea levels as well as change the amounts and patterns of precipitation. Changes in the thermal regime of the climate system and alterations of the physical properties of the underlying surface, certainly affect Earth's climate, and therefore also affect the characteristics of the wind in the atmospheric boundary layer.

The impact of global climate change on wind energy resources has been previously studied for select geographical regions (e.g. [16]-[25]). However, effects of climate change on the wind energy sector in Russia are presently not well explored. This paper analyzes the effects of global climate change on the patterns of the general circulation of the atmosphere, large-scale atmospheric temperature field and dynamics, as well as wind speed in the planetary boundary layer and, in particular, in the atmospheric surface layer, with regards to Russia's geographical location and its climatic characteristics. This paper also explores and discuses current areas of climate change research relevant for estimating the wind energy potential in Russia. Two areas of research are emphasized: study of the impact of global warming on poleward shifts of the large-scale synoptic eddies, which strongly affect the weather patterns and wind field over large territories; and the study of the effects of ice melting in Arctic seas, which significantly alter the properties of the underlying surface and, thus, speed and direction of wind in the surface layer.

This topic is chosen because climate change research needs to focus on improving the analysis and prediction of wind parameters that are most important for wind energy production. It is recommended, that wind farm developers have to take into consideration the effects of climate change on the wind characteristics in the atmos- 
pheric surface layer, so that wind energy production remains beneficial and profitable in the future.

\section{Wind and Main Factors Determining Its Variability}

\subsection{Wind and Its Characteristics}

Wind is the movement of air masses relative to the earth's surface. Wind is caused by differences in atmospheric pressure (pressure gradient): air masses move from regions of high pressure towards to regions of low pressure. The pressure gradient is generated by heterogeneity of heating and cooling of air masses under the influence of radiation, latent heat of condensation of water vapor, as well as turbulent and convective heat transfer. The following forces influence the moving air masses: the Coriolis force due to the Earth's rotation, inertial forces, gravity, and, in the atmospheric boundary layer, the surface force of friction.

For wind energy the practical interest represents the horizontal component of the wind velocity vector, which is usually much larger than the vertical component of the wind speed. The horizontal wind is characterized by two measured parameters: speed and direction from which the wind blows. Wind speed and direction vary in time and space because of turbulence of the air flow and external factors resulting from spatial and temporal heterogeneity of atmospheric temperature and pressure. Variability of wind parameters is characterized by spatial and temporal variations of various scales. Wind speed and direction are measured and defined as values averaged over the certain time interval (usually 2 - $10 \mathrm{~min}$ ).

The wind velocity in the lowest layer of the atmosphere, the atmospheric surface layer, is the most important parameter for wind power generation. The characteristic height of the surface layer is about 100 meters. In this layer turbulent fluxes of momentum, sensible and latent heat are nearly constant with height. The wind speed in the surface layer at a given location may vary within a wide range: from zero to $100 \mathrm{~m} \cdot \mathrm{s}^{-1}$ and even more.

To determine the efficiency of wind energy, a set of parameters is used which includes up to two dozen characteristics. These characteristics can be divided into three groups. The first group includes climatic characteristics that assess wind energy potential of the region in the atmospheric boundary layer such as the average annual and monthly wind speed and direction. The second group includes parameters that define the performance of wind turbines and the selection of their optimum operational regime, for example continuous duration of wind speed and direction within the specified intervals, the frequency distribution of wind speed, information on the duration of calms and wind speeds above a given value. The third group includes wind characteristics used in the design and calculation of the strength and stability of wind turbines: the intensity of atmospheric turbulence, maximum wind speed and gusts, estimates of their duration and frequency.

For wind power energy, the set of important indicators includes also long-term average values of wind characteristics calculated for different time of the day for given month, season and year based on long-term time series of observations. However, in reality the wind parameter variations in a given location can significantly differ from statistical data.

\subsection{Temporal and Spatial Variability of Wind Characteristics}

Wind variability is characterized by the wide-range temporal spectrum: from decadal (climatic variability) and several years (interannual variability) to a few seconds (micro-turbulent variability). For wind power energy, of greatest interest are the temporal variations of wind characteristics (e.g., mean speed) caused by regular natural processes that determine sustained weather and climate variability. For example, Earth's rotation around its axis leads to diurnal variations in the radiation balance of the earth's surface and therefore leads to diurnal variations in temperature, wind characteristics and other meteorological parameters. By averaging the long-term observational data one can obtain the diurnal variation of wind characteristics for each month, season and the whole year. Typically, the diurnal variation of wind characteristics is a periodic function and is characterized by some maximum and some minimum that together determine the amplitude of the diurnal variation. The relative amplitude of the diurnal wind variation depends essentially on the geographic region. In most parts of Russia the relative amplitude of diurnal wind variation is highest in the summer time and can reach $30 \%-40 \%$ with respect to daily average values at the anemometer height [10]. It is important to note that the amplitude of the diurnal variation of the wind characteristics decreases with height.

Inclination of the axis of the Earth's rotation and the rotation in an elliptical orbit around the sun lead to annual variations in solar energy received by the planet, which in turn lead to the substantial changes in the at- 
mospheric general circulation and therefore wind field around the globe. The relative annual changes of wind characteristics on the territory of Russia can reach $40 \%$ - 50\% with respect to mean annual values. There are also long-term and decadal oscillations of the wind climate regime. Interannual oscillations can be regular, generated by periodic changes of radiation regime and processes of large-scale atmosphere-ocean interaction, but also quasi-periodic (e.g., ENSO). The amplitude of interannual wind variations usually reaches $15 \%-20 \%$ with respect to the amplitude of the seasonal and irregular oscillations [10].

Spatial variability of wind is also multiscale: from global and synoptic scale down to the centimeter and millimeter for turbulent fluctuations. The theory of atmospheric general circulation is well-developed and well-described in the literature (e.g., [13] [26]). It is very important to underline, that the main drivers of the earth's atmosphere are the temperature gradient between equator and poles and the earth's rotation which produce the zonal air flow. The equator-to-poles temperature gradient is formed due to the relative position of the earth with respect to the sun, since much more radiation is received by the earth near the equator than in other areas, with the least radiation being received at or near the poles.

\subsection{Local Winds}

An important factor in the formation of the wind climate in the boundary layer of the atmosphere and the surface layer are local winds. Local winds represent the air flows in a certain relatively small geographical region. These winds are created and affected by topographic features, vegetation, water bodies, heterogeneity of the underlying surface etc. Characteristic temporal and spatial scales of local winds and their intensity are determined by the essential features of external forcing that generate local winds. Usually local winds change very often and can move from mild to extreme winds in just hours. These winds have usually names unique to the area where they occur.

Local winds can be subdivided into three general classes. The first contains diurnally varying airflows that are driven by diurnal heating or cooling of the ground surface or by local gradients of surface heat flux (e.g., land and sea breezes, mountain-valley circulations, drainage and slope winds). The second class includes winds generated by the interaction of large-scale airflows with orography. The third group consists of those winds accompanying thermal convective activity.

\section{Climate Change Impacts on Surface Wind Velocity}

\subsection{Climate Change Impacts on the Atmospheric Dynamics}

The sphericity of Earth and the resulting spatially non-uniform distribution of solar heating significantly influence the formation of general circulation of the atmosphere and global three-dimensional configuration of atmospheric winds. It is known, that tropical areas absorb about twice the solar short-wave energy than the polar regions, producing a meridional temperature gradient (MTG) and available potential energy. Some of this energy can be transformed into kinetic energy, which is manifested in the wind. Rotation of the Earth deflects the winds, creating the westerly quasi-zonal airflow which under some conditions can be unstable. Instability of the zonal-flow produces the wave-like atmospheric motions and creates very complicated air flow patterns. The general circulation of the atmosphere plays very important role in redistributing energy, water vapour, latent and sensible heat within the ECS.

There is a large difference between tropical and extratropical atmosphere. In the high and middle latitudes, large-scale atmospheric motions are govern by the nearly perfect balance between the Coriolis force and the pressure gradient. The baroclinic instability of the westerly quasi-zonal flow generates large-scale eddies, cyclones and anticyclones, which dominate the extratropical circulation. The typical length of these eddies is about $4000 \mathrm{~km}$. On the surface weather maps, cyclones (low pressure systems) are located at the ridges of pressurewaves, and anticyclones (high pressure systems), at the troughs of pressure-waves. In the tropics diabatic heating and surface friction affect the circulation since the Coriolis force is weak. One of the most prominent tropical circulation attribute is the Hadley cell (HC). The HC's features include rising motion near the equator, poleward flow 10 - 15 kilometers above the surface, descending motion in the subtropics, and equator-ward flow near the surface. The trade winds and subtropical jet streams are closely related to the HC.

Climate change causes alterations of the radiative balance of the ECS which, in turn, transforms the global and regional temperature structure. It is observed, that the warming is more significant in higher latitudes that in 
lower latitudes. Thus, the temperature difference between the poles and the equator decreases affecting the intensity of global circulation. In particular, it is observed that there is poleward expansion of the tropical circulation (about $0.7^{\circ}$ latitude per decade), which weakens the strength of the mean tropical circulation (e.g. [27] [28]). However, for the extratropical atmospheric dynamics, the intensity changes in the tropical circulation are less important than the poleward movement of the Hadley cell that characterizes the tropical zonal circulation and its width.

The extratropical circulation is also modified under global warming. The most prominent examples of this are the changes in the annual modes, which are the dominant modes of large-scale extratropical variability, manifesting themselves in poleward shifts of the jet streams and storm tracks, increases in the length scale of extratropical eddies, changes in frequency of eddy formation and their intensity [29]. Recent studies show that over the past few decades surface winds have declined in many geographical areas around the world (e.g. [14] [30]-[33]). However, the precise cause of the stilling is not well understood. The comprehensive study of potential cause of changes in surface wind speeds over the mid-latitudes of the Northern Hemisphere between 1979 and 2008, using data from 822 surface weather stations, is represented in [15]. It was observed that surface wind speeds have declined by $5 \%-15 \%$ over almost all continental areas in the northern mid-latitudes, and that strong winds have slowed faster than weak winds. An increase of surface roughness could explain between $25 \%$ and $60 \%$ of the surface wind slowdown [15].

\subsection{Storm Tracks Shifts under Climate Change}

Large-scale extratropical eddies, cyclones and anticyclones, are instrumental for meridional and vertical transporting heat, water vapor and momentum and, thus, they exert strong influence on the weather and climatic conditions over large geographical regions. Cyclones and anticyclones play a significant role in the general circulation of the atmosphere smoothing and leveling temperature contrasts between high and low latitudes [13] [26] [34]. The frequency and intensity of cyclones have a marked influence on the variability of the surface wind velocity, a factor that is very important for wind energy.

Low-pressure systems, cyclones, form the so-called storm tracks, the predominant trajectories of moving cyclonic eddies. Storm tracks are defined as the regions of strong baroclinicity (maximum meridional temperature gradient), which are determined on the basis of eddy characteristics like eddy fluxes of angular momentum, energy, and water vapour. Generally, the climate of Europe and the Western areas of Russia is dominated by weather systems of the extratropical storm tracks. In the Northern Hemisphere, there are two major storms tracks along which most extratropical cyclones travel: Atlantic and Pacific. The behaviour of the storm tracks is highly variable and has a profound impact on the climate of Russian territories. Climate and atmospheric general circulation models, supported by a growing quantity of observational data, have demonstrated that storm tracks shift poleward while the climate becomes warmer. In addition, one can observe the changes in frequency and intensity of cyclones and their length scale. These changes have significant effects on the wind field, in general, and on the surface wind, in particular, over large territories.

The dominant physical mechanism for generating large-scale atmospheric eddies in the high- and mid-latitudes is baroclinic instability of the westerly quasi-zonal atmospheric flow [34]-[36]. Atmospheric static stability and the meridional temperature gradient are the most important fundamental parameters characterizing the development of baroclinic instability and, therefore, the formation and dynamics of extratropical large-scale synoptic eddies. There is evidence of an increase over the past decades of the static stability in the extratropics [37] and a poleward movement of zones with strong MTG-baroclinic zones (e.g. [29] [38] [39]). The MTG produces a vertical shear of the geostrophic wind that forms the westerly quasi-zonal atmospheric air jet. The speed of this flow and its vertical distribution can serve as an indicator of the meridional thermal structure of the atmosphere. Therefore the global warming can be indirectly identified through the speed and vertical shear of the westerly quasi-zonal atmospheric flow. To study how the patterns of this flow and the baroclinic instability have changed in recent decades, a comparative analysis of climates for periods 1949-1968 and 1975-1994 has been carried out using National Center for Environmental Prediction (NCEP) Reanalysis and the European Centre for Medium-Range Weather Forecasting (ECMWF) Reanalysis (ERA40) data [40] [41]. Figure 4 shows the height (in pressure units) and latitudinal cross-section of the zonal wind for the periods 1949-1968 and 1975-1994 as well their difference. One can see that there are significant differences between the two periods. Alterations in the zonal wind caused by changes in the MTG strongly affect the development of baroclinic instability, generation 


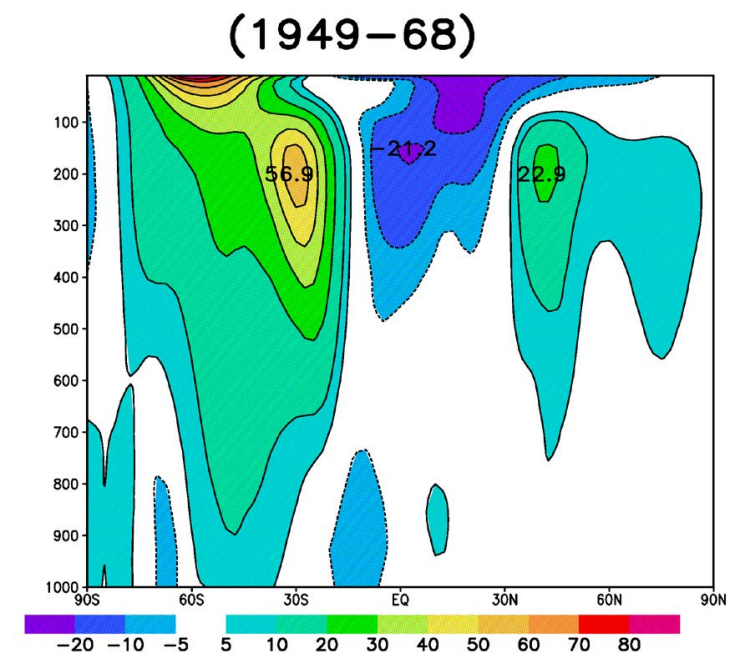

(a)

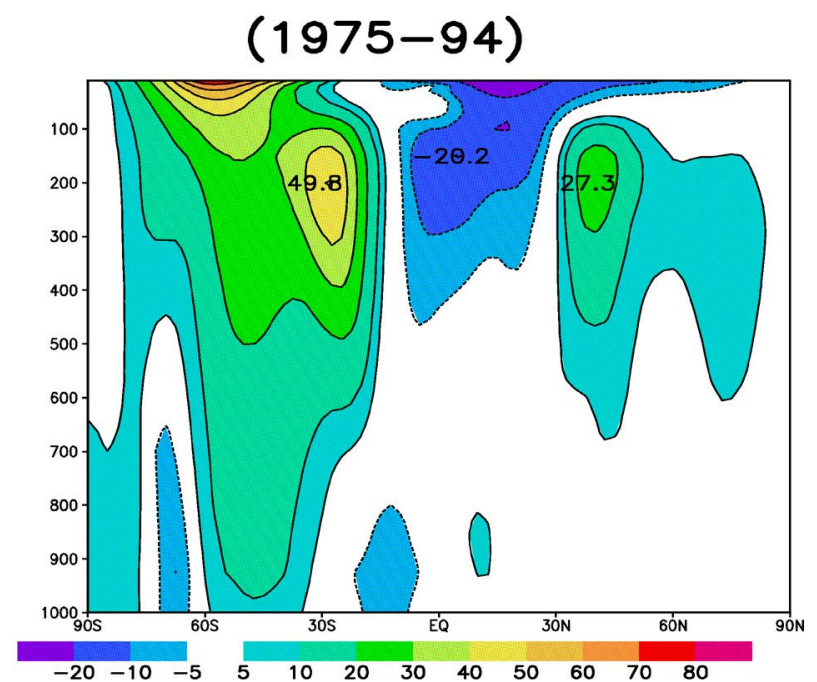

(b)

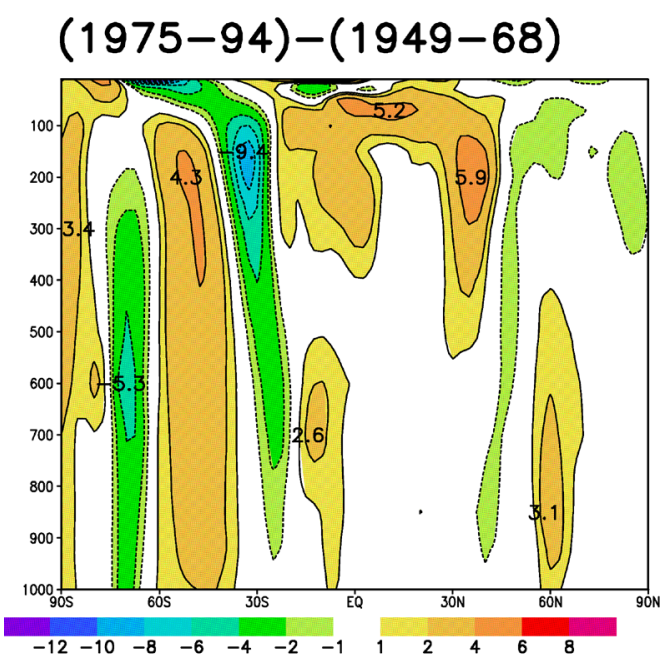

(c)

Figure 4. Vertical cross-section of July zonal wind $\left(\mathrm{m} \cdot \mathrm{s}^{-1}\right)$ as a function of latitude and pressure (in hPa) for the 1949-1968 basic state (a); the 1975-1994 basic state (b and their difference (1975-1994)-(1949-1968) [40].

of large-scale atmospheric eddies and, therefore, surface wind field and its distribution. The impact of variations in the atmospheric static stability and vertical shear of the zonal wind on the main characteristics of baroclinically unstable waves of synoptic scales (e.g. the growth rates of unstable waves as function of wavelength) is explored in [42]. The sensitivity functions obtained in [42] allow estimation, using first-order approximation, of the influence of changes in fundamental atmospheric parameters on the baroclinic instability and formation of synoptic-scale eddies. As an example, Figure 5 shows the sensitivity function $S_{\sigma}$ versus zonal wavenumbers $k_{z}$ for different values of static stability parameter $\sigma_{0}$. The function $S_{\sigma}$ shows changes in the growth rate of unstable waves due to variations in $\sigma_{0}$. The results obtained in [42] are consistent with observations: an increase in static stability and a decrease of the MTG, which occurred over the past few decades in some areas of the globe, have led to the decrease in the growth rate of baroclinic unstable waves, a shift of the spectrum of unstable waves in the long wavelength part of spectrum, and weakened intensity of cyclogenesis. Naturally, these changes affect the formation and development of synoptic eddies as well as the essential features of weather patterns and surface wind velocity over large territories, particularly over Western Russia.

Under global warming, the horizontal length of synoptic eddies is also affected [43]. Cyclones and anticyclones, during the onset of their temporal evolution, are strongly impacted by baroclinic factors. However, after 5 


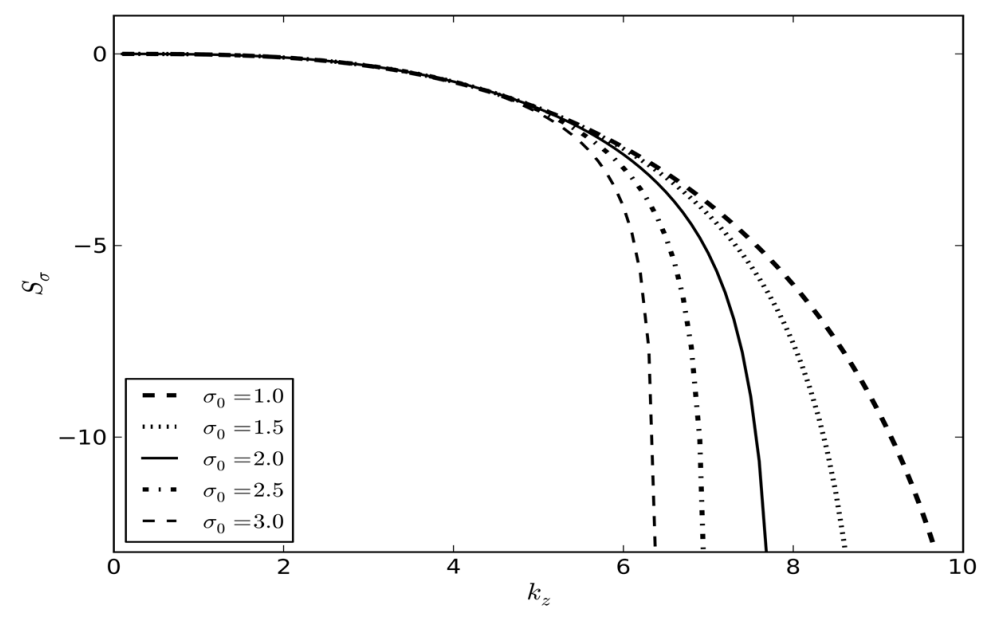

Figure 5. Sensitivity function $S_{\sigma}$ vs. zonal wavenumber $k_{z}$ for different values of the static stability parameter $\sigma_{0}\left(\times 10^{6} \mathrm{~m}^{2} \cdot \mathrm{Pa}^{-2} \cdot \mathrm{s}^{-1}\right)[42]$.

- 7 days of their evolution, large-scale eddies are converted into quasi-vertical quasi-barotropic synoptic objects. A characteristic length of these objects can be estimated by the Obukhov scale

$$
L_{0}=\frac{(g H)^{1 / 2}}{f}=\frac{(R T)^{1 / 2}}{f},
$$

where $g$ is the gravity acceleration, $H$ is the height of the homogeneous atmosphere, $f$ is the Coriolis parameter, $R$ is the gas constant, and $T$ is temperature. Thus, for barotropic atmosphere, the temperature growth causes the increase in $L_{0}$ :

$$
\frac{\mathrm{d} L_{0}}{\mathrm{~d} T_{0}}>0 .
$$

Here, $T_{0}$ is the surface temperature. Typical values of $H$ and $f$ in the extratropical atmosphere are $8.5 \mathrm{~km}$ and $1.1 \times 10^{-4} \mathrm{~s}^{-1}$, respectively, so the Obukhov scale is $L_{0} \approx 2600 \mathrm{~km}$. For baroclinic atmosphere the characteristic length scale of synoptic eddies can be estimated by the Rossby radius of deformation

$$
L_{R}=\frac{(N H)^{1 / 2}}{f}=\frac{1}{f}\left(\frac{T\left(\gamma_{d}-\gamma\right)}{g}\right)^{1 / 2},
$$

where $N$ is the buoyancy frequency, $\gamma_{d}$ is the dry adiabatic lapse rate, $\gamma$ is the reference state lapse rate. Typical value of $N$ in the extratropical atmosphere is $0.01 \mathrm{~s}^{-1}$, so the Rossby radius of deformation is $L_{R} \approx 850 \mathrm{~km}$. In baroclinic atmosphere the influence of the temperature growth on the horizontal size of synoptic-scale eddies is not as clear:

$$
\frac{1}{L_{R}} \frac{\mathrm{d} L_{R}}{\mathrm{~d} T}=\frac{1}{2}\left[\frac{1}{T}-\frac{\mathrm{d} \gamma / \mathrm{d} T}{\left(\gamma_{d}-\gamma\right)}\right] .
$$

Depending on trends in the lapse rate under the influence of global warming, two regimes are possible:

$$
\frac{\mathrm{d} L_{R}}{\mathrm{~d} T_{0}}>0 \text { and } \frac{\mathrm{d} L_{R}}{\mathrm{~d} T_{0}}<0 .
$$

Within the middle latitudes, static stability demonstrates a robust increase [3] with the upper tropospheric warming outpacing the lower tropospheric warming by about $2^{\circ} \mathrm{C}$. Therefore, the atmospheric lapse rate decreases under global warming:

$$
\frac{\mathrm{d} \gamma}{\mathrm{d} T_{0}}<0
$$


Taking into account (5), from (4) one can conclude that in baroclinic atmosphere the characteristic length of synoptic-scale eddies also increases under global warming.

Observational data and results from numerical modeling show that the poleward shift of the storm tracks during the last several decades is not the only observable trend. Additional changes due to climate change include a decrease in occurrence frequency of synoptic-scale eddies and a rise in the intensity of more extreme cyclones [28] [44]. This is believed to be due to the enhanced surface warming in higher latitudes and weaker surface warming in the tropical zone, which leads to a decreasing MTG and the associated atmospheric baroclinicity. The impact of climate change on the trend in the large-scale wave activity of the extratropical atmosphere has been explored in [45] based on the theory of baroclinic instability developed in [46]. The rate of synoptic-scale eddy formation in the extratropical atmosphere can be estimated by the following expression [45]

$$
p^{c}(\Delta S)=\frac{1}{\tau} \frac{4 \cos \varphi \Delta S(\varphi)}{\pi L_{R}^{2} \cos \varphi_{0}},
$$

where $p^{c}$ is the number of large-scale eddies formed per unit of time, $\Delta S(\varphi)$ is the area of the Earth's surface between latitudes $\varphi$ and $\varphi+\Delta \varphi$, and $\tau$ is the increment of growing unstable modes. Expression (6) was obtained under the assumption that the number of eddies formed per unit of time and the intensity of wave activity reach their maxima [47]. Another asymptotic model with the assumption that the number of eddies generated per unit of time $p^{f}$ and the intensity of wave activity reach their minima [47] provides the following formula for $p^{f}$ [45]

$$
p^{f}(\Delta S)=\left(\frac{L_{R}}{L_{0}}\right)^{2} p^{c}(\Delta S)
$$

The global warming causes the increase in both $L_{R}$ and $L_{0}$. Therefore, qualitatively analyzing the equations (6) and (7), one can conclude that, with the increase in global atmospheric temperature, the generation rate of largescale eddies for both asymptotic models decreases. Moreover, since the growth rate of unstable baroclinic waves under global warming decreases, the characteristic time of eddy development $\tau$ increases, so that, according to (6) and (7), the eddy generation rates $p^{c}$ and $p^{f}$ are further reduced. However, with respect to Russian territory, this problem is poorly studied and therefore represents the new area of research. On weather and climatic maps storm tracks indicate geographical areas with significant changes in wind speed and direction in the atmospheric surface layer. The exploration of the storm tracks behavior under global warming and the improvement in our knowledge of the effects of climate change on the extratropical large-scale dynamics, spatial structure and temporal evolution of eddies can be very helpful for estimating the wind energy resources in any particular region of the world.

\subsection{Changes in the Physical Properties of the Underlying Surface}

Wind energy potential is primarily determined by the wind speed in the atmospheric boundary layer (ABL) and, in particular, in the surface layer, which is the lowest part of the ABL. The characteristic height of the atmospheric surface layer, formerly known as the constant flux layer, is about a tenth of the height of the ABL ( $10^{2}$ $\mathrm{m})$. The behavior of the ABL and surface layer is strongly affected by Earth's surface drag and other physical properties of the surface. Thus, in the ABL and the surface layer, physical variables such as wind velocity and direction, temperature and moisture demonstrate quite rapid changes with height and with time. The surface layer dynamics is strongly affected by solar radiation and thus related to the diurnal cycle.

Monin-Obukov similarity theory is usually used to estimate the mean wind speed $u$ at height $z$ above the ground as follows:

$$
u(z)=\frac{u^{*}}{\kappa}\left[\ln \frac{z}{z_{0}}+\Psi\left(\frac{z}{L}\right)\right],
$$

where $u^{*}$ is the friction velocity, $\kappa \approx 0.4$ is the von Karman constant, $z_{0}$ is the surface roughness, $\Psi$ is an empirical function and $L$ is the Monin-Obukhov stability parameter. Function $\Psi$ is the correction to the logarithmic wind profile resulting from the deviation from neutral stratification. Under neutral atmospheric stability conditions, the ratio $z / L$ tends to zero since $L \rightarrow \infty$ and, thus, $\Psi$ drops out. Obviously, the surface roughness is one the most important parameters that affect the vertical wind velocity profile in the surface layer. Table 1 provides 
Table 1. Surface roughness length for various surface types [48].

\begin{tabular}{cc}
\hline Surface type & $z_{0} \mathrm{~m}$ \\
\hline Smooth sea & 0.00001 \\
Rough sea & $0.000015-0.0015$ \\
Ice & 0.00001 \\
Snow & $0.00005-0.0001$ \\
Short grass & $0.04-0.1$ \\
Coniferous forest & $0.28-3.9$ \\
Broadleaf deciduous forest & 2.7 \\
\hline
\end{tabular}

typical surface roughness lengths for different surface types [48].

The impact of topography on large-scale atmospheric motions has been previously explored in the context of numerical modeling (e.g. [49] [50]). The effect of local roughness variations at the Earth's surface on the small-scale atmospheric dynamics has only recently attracted the growing interest from around the world thanks to the rapid development of wind energy generation industry [51]. As mentioned above, the coasts of Russia's Arctic seas offer good opportunities for wind farm development. However, there is evidence of a rapid decline, over the past three decades, of the Arctic sea ice cover during the summer months [9]. Temperature in the Arctic has increased at twice the rate compared to the rest of the globe, and likely will increase by another $8^{\circ} \mathrm{C}$ in the 21st century. Climate simulation results show that the rate of ice cover decline will accelerate (e.g. [52]-[54]) under global warming. The average rate of the Arctic sea ice melting is about $12 \%$ per decade, which suggests the Arctic will be ice-free by 2030 .

Continued decline of the Arctic sea ice at a disastrous rate may dramatically alter regional and global climate and weather patterns in the decades to come. For instance, storm tracks and jet stream will possibly move further north in response to warmer temperatures near the pole, altering the general circulation of the atmosphere and weather patterns around the globe and especially in the Arctic [55]. In addition, melting of the Arctic ice significantly transforms the sea surface, especially in the coastal areas, from snow-covered ice to complex mixtures of ice and melt ponds. Moreover, as a result of global warming the large ice-free areas (polynyas) occur close to the coast. Many polynyas may freeze during the peak of winter. The large polynyas, however, can stay open all winter. Consequently, these lead to an increase in the sea surface roughness length $z_{0}$. Changes in the surface roughness in the Arctic sea coastal areas decrease the wind speed in the ABL, influencing the exchanges of heat, moisture and momentum between the atmosphere and surface, affecting the synoptic scale pressure field, and resulting in changes in regional circulation patterns. The surface roughness $z_{0}$ of sea ice is also affected by ridges, floe edges and patterns formed of drifting snow. Observations show that the parameter $z_{0}$ has wide range of variations: from $0.3 \mathrm{~mm}$ up to $30 \mathrm{~mm}$ [56]. Thus, under global warming, the surface of the Arctic sea in coastal areas becomes very heterogeneous and rapidly changing, which, in turn, has a strong influence on the wind speed in the ABL and surface layer of the atmosphere.

To estimate the influence of variations in $z_{0}$ on the wind speed in the ABL $u$, one can use the sensitivity function $S$, which is the derivative of $u$ with respect to $z_{0}$. The expression for $S$ can be obtained by differentiating (8) with respect to $\mathrm{z}_{0}$ :

$$
S=\frac{\partial u}{\partial z_{0}}=-\frac{u^{*}}{\kappa z} z_{0}^{-1} .
$$

Sensitivity function $S$ shows changes in $u$ due to variations in $z_{0}$ and is evaluated in the vicinity of some basic value of the parameter $z_{0}$. In general, several basic values can be selected to cover some range of changes in $z_{0}$. Let's calculate the sensitivity function for $z=50 \mathrm{~m}$. Typical value of $u^{*}$ is $0.2 \mathrm{~m} \cdot \mathrm{s}^{-1}$, therefore

$$
S_{50} \approx-10^{-2} \times z_{0}^{-1} \text {. }
$$

Assuming the surface roughness parameter for snow-covered ice is $z_{0}=10^{-4} \mathrm{~m}$, the sensitivity is $S_{z=50} \approx 10^{2} \mathrm{~s}^{-1}$. If $\delta z_{0}$ is a variation in the parameter $z_{0}$, then the change in the wind speed $\delta u$ at a given height $z$ due to $\delta z_{0}$ can be 
estimated as follows

$$
\delta u(z)=S \times \delta z_{0}+\mathcal{O}\left[\left(\delta z_{0}\right)^{2}\right] .
$$

For example, if $\delta z_{0} \approx 10^{-2} \mathrm{~m}$, then $\delta u \approx 1 \mathrm{~m} \cdot \mathrm{s}^{-1}$. This result has an illustrative character, showing strong dependence of the surface layer wind speed on the surface roughness.

Therefore, melting of the Arctic sea ice has a wide range of impacts on the global and regional atmospheric dynamics. The study of how global warming affects the sea surface roughness and, as a result, the wind speed in the Arctic coastal regions represents a current area of research interest, and call for both field experiments as well as theoretical explorations.

\section{Conclusions}

Observational data and climate simulation results indicate that the Earth's global temperature has been consistently rising over past several decades with more rapid rising seen over last three decades. Global temperature will likely continue to grow in the next decades. Climate change influences not only the temperature regime of the ECS globally and regionally, but also the atmospheric dynamics - the general circulation of the atmosphere, regional and local winds. The global warming is a human-made phenomenon caused by the increase of GHG concentrations in the atmosphere. Using renewable energy, wind energy in particular, to reduce the negative consequences of the global warming should be considered as a possible option. However, the wind energy production is a function of the state and variability of the ECS. Previous studies have shown that over the last three decades measured wind in the boundary and surface layer of the atmosphere has changed significantly around the world. At the same time, estimates of climate change on the wind energy sector of Russia are not well explored.

Developers of wind farm projects should take into consideration potential impact of climate change on the operation, financial expectations and potential benefits of wind generation facilities. Therefore, exploration of impact of climate change on wind changes in the areas suitable for wind farm development is a focus of current feasibility studies and research. This paper discussed the analysis of the effects of climate change on the general circulation of the atmosphere, large-scale atmospheric dynamics and wind speeds in the ABL and surface layer, and considered geographical regions suitable for potential development of wind farm projects. Two current areas of research were emphasized: First, the study of the global warming impact on the formation and evolution of the synoptic-scale eddies and storm tracks associated with prevailing trajectories of the movement of cyclones; Second, the exploration of the influence of melting ice in Arctic coastal areas on changes in the surface roughness length. This parameter significantly influences the wind speed in the atmospheric surface layer.

Traditionally, feasibility studies and meteorological assessment conducted at potential areas for the development of wind farm projects are based on the wind climatology. For the most part, these studies ignore changes in weather patterns that may be connected with the global warming, such as alterations of wind patterns, poleward shifts of storm tracks, changing length scale of cyclones, increasing number of intense cyclones with high wind velocities, and modified wind speeds. Consequently, the results of feasibility studies can contain uncertainty, which increases with the life cycle period of wind farms (20 - 30 years). In conclusion, to improve the accuracy of feasibility studies, it is essential that potential effects of global warming are fully taken into account.

\section{References}

[1] WWEA (2014) Key Statistics of World Wind Energy Report 2013. WWEA, Shanghai, 7 April 2013, 13 p.

[2] Rogner, H.H., Barthel, F., Cabrera, M., Faaij, A., Giroux, M., Hall, D., Kagramanian, V., Kononov, S., Lefevre, T., Moreira, R., Notstaller, R., Odell, P. and Taylor, M. (2000) Energy Resources. In: World Energy Assessment, Energy and the Challenge of Sustainability, United Nations Development Program United Nations Department of Economics and Social Affairs, and World Energy Council, New York, 135-171.

[3] Grubb, M.J. and Meyer, N.I. (1993) Wind Energy: Resources, Systems and Regional Strategies. In: Johansson, T.B., Kelly, H., Reddy, A.K.N. and Williams, R.H., Eds., Renewable Energy: Sources for Fuels and Electricity, Island Press, Washington DC, 157-212.

[4] Archer, C.L. and Jacobson, M.Z. (2005) Evaluation of Global Wind Power. Journal of Geophysical Research, 110, Article ID: D12110.

[5] Lu, X., McElroy, M.B. and Kiviluoma, J. (2009) Global Potential for Wind-Generated Electricity. Proceedings of the 
National Academy of Sciences of the USA, 106, 10933-10938. http://dx.doi.org/10.1073/pnas.0904101106

[6] Jacobson, M.Z. and Archer, C.L. (2012) Saturation Wind Power Potential and Its Implications for Wind Energy. Proceedings of the National Academy of Sciences of the USA, 109, 15678-84.

[7] Marvel, K., Kravitz, B. and Caldera, K. (2012) Geophysical Limits to Global Wind Power. Nature Climate Change, 3, 118-121. http://dx.doi.org/10.1038/nclimate1683

[8] Adams, A.S. and Keith D.W. (2013) Are Global Wind Power Resource Estimates Overstated? Environmental Research Letters, 8, Article ID: 015021.

[9] Wiser, R., Yang, Z., Hand, M., Hohmeyer, D., Infield, D., Jensen, P.H., Nikolarv, V., O’Malley, M., Sinden, G. and Zervos, A. (2011) Wind Energy. In: Edenhofer, R., Pichs-Madruga, R., Sokona, Y., Seyboth, K., Matschoss, P., Kadner, S., Zwickel, T., Eickemeier, P., Hansen, G., Schlomer, S., and von Stechow, C., Eds., IPCC Special Report on Renewable Energy Sources and Climate Change Mitigation, Cambridge University Press, Cambridge, UK and New York. http://dx.doi.org/10.1017/CBO9781139151153.011

[10] Nikolaev, V.G., Ganaga, S.V. and Kudriashiv, K.I. (2008) National Inventory of Wind Resources of Russia and Methodological Foundations for Their Determination. Atmograph, Moscow, 590 p.

[11] Starkov, A.N., Landberg, L., Bezroukikh, P.P. and Borisenko, M.M. (2000) Russian Wind Atlas. Russian-Danish Institute for Energy Efficiency, Moscow: Risø National Laboratory, Roskilde, 551 p.

[12] Dmitriev, G. (2001) Wind Energy in Russia. VetrEnergo for Gaia Apatity and INFORSE-Europe. http://www.inforse.org/europe/word docs/ruswind2.doc

[13] Lorenz, E.N. (1967) The Nature and Theory of the General Circulation of the Atmosphere. World Meteorological Organization.

[14] Pryor, S.C., Barthelmie, R.J., Toung, D.T., Takle, E.S., Arrit, R.W., Flory, D., Gutovsky, W.J. and Roads, J. (2009) Wind Speed Trends over the Contiguous United States. Journal of Geophysical Research: Atmospheres, 114, Published Online. http://dx.doi.org/10.1029/2008JD011416

[15] Vautard, R., Cattiaux, J., Yiou, P., Thepaut, J.N. and Ciais, P. (2010) Northern Hemisphere Atmospheric Stilling Partly Attributed to an Increase in Surface Roughness. Nature Geoscience, 3, 756-761. http://dx.doi.org/10.1038/ngeo979

[16] Pryor, S.C., Barthelmie, R.J. and Kjellström, E. (2005) Potential Climate Change Impact on Wind Energy Resources in Northern Europe: Analyses Using a Regional Climate Model. Climate Dynamics, 25, 815-835. http://dx.doi.org/10.1007/s00382-005-0072-x

[17] Harrison, G.P., Cradden, L.C. and Chick, J.P. (2008) Preliminary Assessment of Climate Change Impacts on the UK Onshore Wind Energy Resource. Energy Sources, Part A: Recovery, Utilization, and Environmental Effects, 30, 12861299. http://dx.doi.org/10.1080/15567030701839326

[18] Pryor, S.C. and Barthelmie, R.J. (2002) Comparison of Potential Power Production at On- and Off-Shore Sites. Wind Energy, 4, 173-181. http://dx.doi.org/10.1002/we.54

[19] Pryor, S.C. and Barthelmie, R.J. (2003) Long-Term Trends in Near-Surface Flow over the Baltic. International Journal of Climatology, 23, 271-289. http://dx.doi.org/10.1002/joc.878

[20] Pryor, S.C. and Barthelmie, R.J. (2010) Climate Change Impacts on Wind Energy: A Review. Renewable and Sustainable Energy Reviews, 14, 430-437. http://dx.doi.org/10.1016/j.rser.2009.07.028

[21] Breslow, P.B. and Sailor, D.J. (2002) Vulnerability of Wind Power Resources to Climate Change in the Continental United States. Renewable Energy, 27, 585-598. http://dx.doi.org/10.1016/S0960-1481(01)00110-0

[22] Sailor, D.J., Smith, M. and Hart, M. (2008) Climate Change Implications for Wind Power Resources in the Northwest United States. Renewable Energy, 33, 2393-2406. http://dx.doi.org/10.1016/j.renene.2008.01.007

[23] Wang, C. and Prinn, R.G. (2009) Potential Climatic Impacts and Reliability of Very Large-Scale Wind Farms. Report No. 175, MIT, Cambridge.

[24] Nolan, P., Lynch, P., McGrath, R., Semmler, T. and Wang, S. (2012) Simulating Climate Change and Its Effects on the Wind Energy Resource of Ireland. Wind Energy, 15, 593-608. http://dx.doi.org/10.1002/we.489

[25] Hueging, H., Haas, R., Born, K., Jacob, D. and Pinto, J.G. (2013) Regional Changes in Wind Energy Potential over Europe Using Regional Climate Model Ensemble Projections. Journal of Applied Meteorology and Climatology, 52, 903-917. http://dx.doi.org/10.1175/JAMC-D-12-086.1

[26] Masaki, S. (2014) Atmospheric Circulation Dynamics and General Circulation Models. Springer-Verlag, New York.

[27] Lu, J., Vechhi, G.A. and Reichler, T. (2007) Expansion of the Hadley Cell under Global Warming. Geophysical Research Letters, 34, Published Online.

[28] Reichler, T. (2009) Changes in the Atmospheric Circulations as Indicator of Climate Change. In: Letcher, T.M., Ed., Climate Change: Observed Impacts on Planet Earth, Elsevier, Amsterdam, 145-164. http://dx.doi.org/10.1016/B978-0-444-53301-2.00007-5 
[29] Bengtsson, L., Hodges, K.I. and Roeckner, E. (2006) Storm Tracks and Climate Change. Journal of Climate, 19, 3518-3543. http://dx.doi.org/10.1175/JCLI3815.1

[30] Kink, K. (1999) Trends in Monthly Maximum and Minimum Surface Wind Speeds in the Coterminous United States, 1961 to 1990. Climate Research, 13, 193-205. http://dx.doi.org/10.3354/cr013193

[31] Pirazzoli, P.A. and Tomasin, A. (2003) Recent Near-Surface Wind Changes in the Central Mediterranean and Adriatic Areas. International Journal of Climatology, 23, 963-973. http://dx.doi.org/10.1002/joc.925

[32] Pryor, S.C., Barthelemie, R.J. and Schoof, J.T. (2005) Inter-Annual Variability of Wind Indices across Europe. Wind Energy, 9, 27-38. http://dx.doi.org/10.1002/we.178

[33] Smits, A., Klein-Tank, A.M.G. and Können, G.P. (2005) Trends in Storminess over the Netherlands, 1962-2002. International Journal of Climatology, 25, 1331-1344. http://dx.doi.org/10.1002/joc.1195

[34] Charney, J.G. (1947) The Dynamics of Long Waves in Baroclinic Westerly Current. Journal of Meteorology, 4, 136162. http://dx.doi.org/10.1175/1520-0469(1947)004<0136:TDOLWI>2.0.CO;2

[35] Holton, J.R. (1992) An Introduction to Dynamic Meteorology. 3rd Edition, Academic Press, New York.

[36] Eady, E.T. (1949) Long Waves and Cyclone Waves. Tellus, 1, 33-52. http://dx.doi.org/10.1111/j.2153-3490.1949.tb01265.x

[37] Frierson, D.M.W. (2006) Robust Increases in Midlatitude Static Stability in Simulations of Global Warming. Geophysical Research Letters, 33, Published Online. http://dx.doi.org/10.1029/2006GL027504

[38] Hall, N.M.J., Hoskins, B.J., Valdes, P.J. and Senior, C.A. (1994) Storm Tracks in a High-Resolution GCM with Doubled Carbon Dioxide. Quarterly Journal of the Royal Meteorological Society, 120, 1209-1230. http://dx.doi.org/10.1002/qj.49712051905

[39] Yin, H. (2005) A Consistent Poleward Shift of the Storm Tracks in Simulations of 21st Century Climate. Geophysical Research Letters, 32, Published Online. http://dx.doi.org/10.1029/2005GL023684

[40] Frederiksen, J.S. and Frederiksen, C.S. (2007) Interdecadal Changes in Southern Hemisphere Winter Storm Track Modes. Tellus, 59, 599-617. http://dx.doi.org/10.1111/j.1600-0870.2007.00264.x

[41] Frederiksen, C.S., Frederiksen, J.S., Sison, J.N. and Williams, R.H. (2011) Observed and Projected Changes in the Annual Cycle of Southern Hemisphere Baroclinicity for Storm Formation. Proceedings of the 19th International Congress on MODSIM, Perth, 12-16 December 2011, 2719-2725

[42] Soldatenko, S.A. and Tingwell, C. (2013) The Sensitivity of Characteristics of Large Scale Baroclinic Unstable Waves in Southern Hemisphere to the Underlying Climate. Advances in Meteorology, 2013, Article ID: 9812711. http://dx.doi.org/10.1155/2013/981271

[43] Kidston, J., Dean, S.M., Renwick, J.A. and Vallis, G.K. (2010) A Robust Increase in the Eddy Length Scale in the Simulation of Future Changes. Geophysical Research Letters, 37, Published Online. http://dx.doi.org/10.1029/2009GL041615

[44] Mizuta, R., Matsueda, M., Endo, H. and Yukimoto, S. (2011) Future Changes in Extratropical Cyclones Associated with Change in the Upper Troposphere. Journal of Climate, 24, 6456-6470. http://dx.doi.org/10.1175/2011JCLI3969.1

[45] Mokhov, I.I., Mokhov, O.I., Petukhov, V.K. and Khairullin, R.R. (1992) On Trends of Atmospheric Cyclogenesis Activity under Climate Change. Atmospheric and Oceanic Physics, 28, 11-26.

[46] Phillips, N.A. (1954) Energy Transformation and Meridional Circulation Associated with Simple Baroclinic Waves in a Two-Level, Quasi-Geostrophic Model. Tellus, 6, 273-286. http://dx.doi.org/10.1111/j.2153-3490.1954.tb01123.x

[47] Palmen, E. and Newton, C.W. (1969) Atmospheric Circulation System. Academic Press, New York.

[48] Jacobson, M.Z. (2005) Fundamental of Atmospheric Modeling. Cambridge University Press, Cambridge. http://dx.doi.org/10.1017/CBO9781139165389

[49] Hoskins, B.J. (1983) Dynamical Processes in the Atmosphere and the Use of Models. Quarterly Journal of the Royal Meteorological Society, 109, 1-21. http://dx.doi.org/10.1002/qi.49710945902

[50] Cook, K.H. and Held, I.M. (1992) The Stationary Response to Large-Scale Orography in a General Circulation Model and a Linear Model. Journal of the Atmospheric Sciences, 49, 525-539. http://dx.doi.org/10.1175/1520-0469(1992)049<0525:TSRTLS>2.0.CO;2

[51] Kirk-Davidoff, D.B. and Keith, D.W. (2008) On the Climate Impact of Surface Roughness Anomalies. Journal of the Atmospheric Sciences, 65, 2215-2234. http://dx.doi.org/10.1175/2007JAS2509.1

[52] Comiso, J., Parkinson, C., Gertsen, R. and Stock, L. (2008) Accelerated Decline in the Arctic Sea Ice Cover. Geophysical Research Letters, 35, Published Online. http://dx.doi.org/10.1029/2007GL031972

[53] Kumar, A., Perlwitz, J., Eischeid, J., Quan, X., Xu, T., Zhang, T., Hoerling, M., Jha, B. and Wang, W. (2010) Contribution of Sea Ice Loss to Arctic Amplification. Geophysical Research Letters, 37, Published Online. 
http://dx.doi.org/10.1029/2010GL045022

[54] Petoukhov, V. and Semenov, V.A. (2010) A Link between Reduced Barents-Kara Sea Ice and Cold Winter Extremes over Northern Continents. Journal of Geophysical Research: Atmospheres, 115, Published Online. http://dx.doi.org/10.1029/2009JD013568

[55] Jaiser, R., Dethloff, K., Handorf, D., Rinke, A. and Cohen, J. (2012) Impact of Sea Ice Cover Changes on the Northern Hemisphere Atmospheric Winter Circulation. Tellus, 64, 11595. http://dx.doi.org/10.3402/tellusa.v64i0.11595

[56] Guest, P.S. and Davidson, K.L. (1991) The Aerodynamic Roughness of Different Types of Sea Ice. Journal of Geophysical Research: Oceans, 96, 4709-4721. http://dx.doi.org/10.1029/90JC02261 
Scientific Research Publishing (SCIRP) is one of the largest Open Access journal publishers. It is currently publishing more than 200 open access, online, peer-reviewed journals covering a wide range of academic disciplines. SCIRP serves the worldwide academic communities and contributes to the progress and application of science with its publication.

Other selected journals from SCIRP are listed as below. Submit your manuscript to us via either submit@scirp.org or Online Submission Portal.
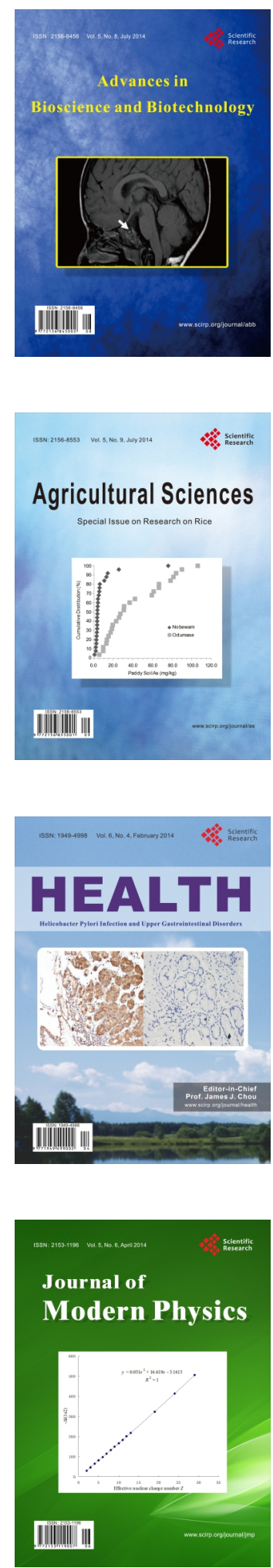
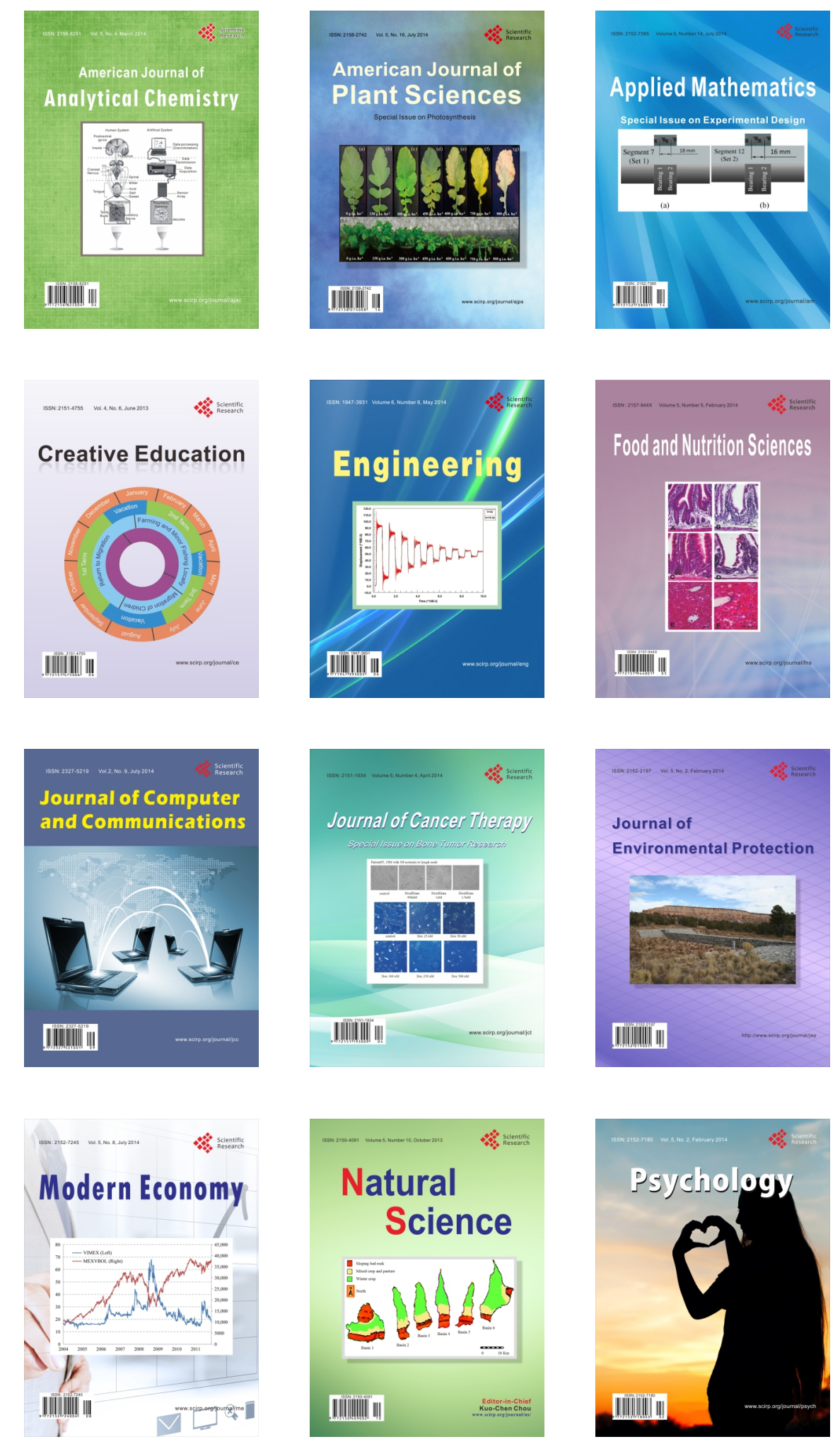